\title{
Educational Experiences of Undergraduate Male Nursing Students: A Focus Group Study
}

\author{
Alia Mahadeen ${ }^{1 *}$, Lubna Abushaikha1, Samira Habashneh ${ }^{2}$ \\ ${ }^{1}$ School of Nursing, The University of Jordan, Amman, Jordan \\ ${ }^{2}$ School of Nursing, Al Ahaliyya Amman University, Salt, Jordan \\ Email: a.mahadeen@ju.edu.jo,1.Abushaikha@ju.edu,samira.habashneh@gmail.com
}

How to cite this paper: Mahadeen, A., Abushaikha, L. and Habashneh, S. (2017) Educational Experiences of Undergraduate Male Nursing Students: A Focus Group Study. Open Journal of Nursing, 7, 50-57. http://dx.doi.org/10.4236/ojn.2017.71005

Received: November 7, 2016

Accepted: January 15, 2017

Published: January 18, 2017

Copyright @ 2017 by authors and Scientific Research Publishing Inc. This work is licensed under the Creative Commons Attribution International License (CC BY 4.0).

http://creativecommons.org/licenses/by/4.0/

(c) † Open Access

\begin{abstract}
Background: The educational experiences of undergraduate male nursing students in developing countries such as Jordan have yet to be fully investigated in the literature. Purpose: The purpose of this study was to explore the educational experiences of Jordanian undergraduate male nursing students. Methods: A qualitative research design using inductive content analysis approach was used to explore educational experiences of undergraduate male nursing students at a prominent public university. Focus group interviews were used to obtain information of an interactive, conversational nature from male nursing students and to gain in-depth insight regarding their educational experiences. Twenty undergraduate male nursing participants representing the four academic levels of a nursing program were recruited. Four focus groups ranging between 4 - 6 students were used to gather data. Inductive content analysis was used. Results: Three themes emerged from this study: "nursing: a deliberate choice", "nursing is wonderful yet challenging", and "nursing is not for men". Students articulated that they deliberately chose to study nursing and to enter this academic field. Participants indicated that studying nursing was a wonderful experience that was intertwined with several challenges. Students from different levels explicitly emphasized that they were challenged and bombarded with enduring negative stereotypes and negative societal views regarding males in nursing. Conclusions and Implications: Findings illustrated that educational experiences of undergraduate male nursing students varied between wonderful experiences upon deliberate entry into nursing programs to enduring negative stereotypes and views regarding male nurses. Nursing educators are expected to comprehend the educational experiences of their students, particularly male students, and provide counseling, role-modeling and support as needed. Additionally, nurse educators should encourage all students to
\end{abstract}

*This study was done during sabbatical leave 2012/2013. 
manage gender related problems by emphasizing a nurse's role identity without gender segregation or discrimination.

\section{Keywords}

Nursing Education, Academic Experiences, Nursing, Jordan, Male Student

\section{Introduction}

In nursing discipline, men are considered minorities facing many obstacles in their education and professional careers which include negative stereotypes, gender discrimination, and restricted employment [1] [2] [3]. In the past 30 years, literature focusing on the educational experiences of male nursing students has highlighted the influence of gender issues on nursing education and the development of a nursing identity [1] [4]. Moreover, most of the published studies have been conducted with different student populations within different programs (i.e. diploma, baccalaureate) in several industrial countries [5] [6] [7] [8]. Yet, there is still a need for more studies that focus on gaining a holistic understanding of the educational experiences from the perspectives of male nursing students in developing countries such as Jordan. Jordan is relatively a small country that has witnessed a shortage in nurses and a rapid increase in the number of male nurses in the nursing workforce. During the last two decades, interest in studying nursing has increased tremendously, especially among males. In 2007, there are thirteen nursing programs awarding a bachelor degree in nursing [9] [10] It becomes important to consider maintaining male nurses in the nursing field and promote a professional nursing image and enhance its standing in the community, especially for men. This study aimed to explore the educational experiences of Jordanian undergraduate male nursing students.

\section{Methods}

\subsection{Design}

A qualitative approach (Qualitative research is about exploring issues, understanding phenomena, and answering questions by analyzing and making sense of unstructured data) was used to describe the educational experiences of undergraduate male nursing students. Focus group interviews were used to obtain information of an interactive, conversational nature from male nursing students and to gain in-depth insight regarding their educational experiences [11] [12].

\subsection{Sample Selection}

Purposive sampling was used to select 20 Jordanian male nursing students from different academic levels (i.e. first year to fourth year) was employed in this study. Students were intentionally and purposively recruited to represent varied aspects of educational experiences of male nursing students enrolled in an undergraduate program in a prominent public university during their course of study. Addi- 
tionally, students from different academic levels had significant contributions and feedback to offer about their recent experiences in nursing education, since they communicated significant ideas and represented their learning experiences very well. Participants were included in the study if they were male undergraduate nursing students, currently studying in one of the Jordanian nursing baccalaureate program in Jordan. Also, they were willing to participate in the study. Students who were recently enrolled in the nursing program were excluded because they lack the required experience.

\subsection{Ethical Considerations}

The study was approved by the scientific research ethics committee. Informed consent was obtained from all students and they had the option to withdraw from the study at any time and for any reason. To minimize bias, the moderators of the focus group discussions had no prior contact with or personal knowledge of the students at the time of data collection. The tapes and transcripts of the interviews were kept in a locked file accessible only to the investigators. Privacy was maintained to protect the identities of participants and confidentiality of the conveyed information was also assured.

\subsection{Data Collection}

The Procedure: After obtaining informed consent, participants completed a demographic data sheet. Four focus groups ranging between 4 - 6 students representing the four years of the undergraduate program were interviewed regarding their educational experiences [11]. The main interview question was "As a male nursing student, can you describe your nursing educational experience?" Focus group discussions were audiotape and participants in each focus group were given the appropriate time to express their ideas and talk freely regarding their personal experiences and views. The discussions were scheduled in agreement with the students and conducted in a designated quiet room at the faculty of nursing. Focus group discussions ranged between $30-70$ minutes in length. To maintain rigor and credibility of the study findings, data analysis occurred independently by the researchers and themes were compared and discussed until consensus was achieved. Additionally two independent qualitative researchers determined the trustworthiness of the final themes through peer review [11] [12].

\subsection{Data Analysis}

All focus group interviews were transcribed verbatim, and phrases were obtained from the collected data which were reexamined to ensure consistency, then codes and themes were developed. In our study, inductive content analysis was used in data analysis. The process of data analysis entailed becoming familiarized with the data; open coding and creating categories after all written material were read more than once to comprehend all aspects of the content. Subsequently, categories were grouped based on similarities and three major themes 
were generated.

\section{Results}

\subsection{Subject Characteristics}

General characteristics of participants are presented in Table 1. Participants were selected from different academic levels 20 male nursing students for their first ( $n$ $=5)$, second $(n=5)$, third $(n=5)$ and fourth $(n=5)$ years of study and aged 18 22 years.

\subsection{Content Analysis}

Content analysis revealed three major themes emerged from the data analysis included: Nursing: a deliberate choice; nursing is wonderful yet challenging; and nursing is not for men.

\subsubsection{Nursing: A Deliberate Choice}

Students articulated that they deliberately chose to study nursing and to enter this academic field. According to participants, the decision to study nursing was influenced by several factors including wanting to be a nurse to help people; having relatives that worked in health fields such as medicine; and having an interest in health-related specialties.

I love nursing and chose it willingly. By the way, it has nothing to do with grades. I like the hospital environment and patients. I like to help them and try to ease their sickness. For me, nursing is humanistic ( $1^{\text {st }} \mathrm{yr}$ focus group).

From the beginning, after finishing $10^{\text {th }}$ grade I wanted nursing. I used to visit my uncle who was a doctor several times so I entered the health fields from the beginning. I saw the system in the hospital how patients rely mostly on nurses not doctors. Nurses' work 24 hours their job is great from this perspective $\left(1^{\text {st }} \mathrm{yr}\right.$ focus group).

Frankly, my mother and father are sick. I chose nursing to help them at home, so I entered into nursing ( $3^{\text {rd }} \mathrm{yr}$ focus group). It is nice to help people and have a positive role in life ( $4^{\text {th }} \mathrm{yr}$ focus group).

\subsubsection{Nursing Is Wonderful yet Challenging}

Participants indicated that studying nursing was a wonderful experience that

Table 1. General characteristics of participants $(\mathrm{N}=20)$.

\begin{tabular}{cccc}
\hline Characteristics & Categories & $\mathbf{n}$ & $\%$ \\
Age & $18-20$ & 7 & $35 \%$ \\
Gender & $21-22$ & 13 & $65 \%$ \\
Religion & Male & 20 & $100 \%$ \\
Marital status & Choslem & 19 & $95 \%$ \\
\hline
\end{tabular}


was intertwined with several challenges. Students explained that they faced several difficulties and challenges during the course of their study that included acclimating to the new and unknown academic environment, dealing with demanding study workloads, and lack of time to manage different responsibilities. Participants proclaimed that although the gained knowledge was very interesting and appreciated, there was a consensus among students that studying nursing is not easy and entailed enduring the stress and strain of exams and clinical training.

For me, it was very fun and very difficult. The specialty was fun and wonderful from a work perspective. First of all, I didn't know what nursing was a wonderful experience although it had negative things. My experience was valuable and I gained knowledge and clinical skills ( $4^{\text {th }} \mathrm{yr}$ focus group).

When we first entered the program, we did not have any background about the courses at all. It needs studying through and through and follow-up on your studying. You have to be focused and write everything and follow the professor ( $1^{\text {st }}$ yr focus group).

Nursing is a challenge... a new place... you come to a new environment and you do not know anybody. Now we have friends, we like to study and we get high grades ( $3^{\text {rd }} \mathrm{yr}$ focus group). The required material is too much you have to follow up on the lecture. We spend too much time understanding the material $\left(2^{\text {nd }} \mathrm{yr}\right.$ focus group).

\subsubsection{Nursing Is Not for Men}

Students from different levels explicitly emphasized that from the beginning of their educational experiences they were challenged and bombarded with enduring negative stereotypes and negative societal views regarding males in nursing. As students, they experienced rejection and mistrust and were confronted with popular views of nursing as a female profession. The negative stereotypes and views were experienced by participants throughout their course of study and were also voiced by other men in the form of male patients, male doctors, and male colleagues.

When someone asks me what am I studying and I say nursing they ask why? What are you going to do with it? Couldn't you find anything else? ( $1^{\text {st }} \mathrm{yr}$ focus group).

Society has an inferior view of nursing. Although there are a lot of jobs in nursing in nursing colleges there are not a lot of male students. In one course, we had 75 female students and only 2 male students ( $2^{\text {nd }} \mathrm{yr}$ focus group). Nursing is for girls... I heard this statement a lot ( $3^{\text {rd }} \mathrm{yr}$ focus group).

"One time I was in the hospital during the adult health rotation and I was assigned a male patient with a case of falling down. When I came in the room he asked me if I was a doctor, I said no I am a nursing students; so he said to the staff I don't want male nursing students to work with me ( $4^{\text {th }} \mathrm{yr}$ focus group).

\section{Discussion}

The purpose of our study was to gain an overall understanding of the education- 
al experiences of male nursing students in an undergraduate nursing program in Jordan. Studying nursing, as any experience, entails both positive and negative aspects that influence individual perceptions. In general, nursing students fall under one of two groups: those who purposefully choose nursing and those who enter into nursing due to lack of other alternatives. Hence, choosing to study nursing and enter into professional practice are not easy decisions.

Our findings supported evidence in international literature which depicts male nursing students deliberately choosing to study nursing. Jordanian male nursing students, similar to other male nursing students in the world, reported that were happy to enter into a specialty that they liked and to begin the career of their choice. Students also viewed nursing as a caring, humanistic profession which leads to helping others and providing valuable services to society [3] [13] [14]. However, some students reported that although they entered nursing willingly, they did not make this choice based on a full understanding of nursing education. Students implied the absence of orientation programs that help recruit future nursing students that may help them in making "informed decisions" regarding their education.

In this study, participants perceived nursing as wonderful experience that was intertwined with several challenges. According to students, studying nursing is a mix of both positive and negative events. Students valued the importance of knowledge, skills and personal growth gained from different nursing courses, yet they were astounded by the burden of adapting to a new environment, time management, the intensity of exams and clinical rotations. This finding was particularly true for freshmen and sophomores who were still in the process of learning the nature of nursing and adapting to entry level courses and clinical experiences [15] [16] [17].

Our study furthermore reiterated common ideas of nursing as a female-dominant profession with limited space for masculinity. Males still struggle with being accepted into nursing programs and the nursing workforce, despite the improved status of male nurses in the world [16] [18] [19]. Male nursing students emphasized several sentiments regarding negative views and stereotypes that they encountered throughout the different academic levels [8] [20] [21] [22]. From freshmen to seniors, students faced rejection and mistrust from others, solely based on their gender. Gender identity, gender roles, and gender discrimination in nursing remain salient and debatable issues that require reevaluation and review [23] [24] [25].

\section{Limitations}

Small sample number could be considered as limitation for this study .However the participants were selected as purposeful sample considering the maximum variation of the participants (years of study, age, and gender). Also, all the interviews were conducted by a female researcher which may influence the participants sharing their full experience.

\section{Conclusion and Recommendation}

The study findings demonstrated three major themes emerged from the data 
analysis including: students deliberately chose to study nursing, perceived nursing as wonderful experience that was intertwined with several challenges, and thought that nursing is not for men. However, the study findings indicated that male nursing students emphasized several sentiments regarding negative views and stereotypes that they encountered throughout the different academic levels. The results of this study may help in providing evidence-based criteria for the gender-role perceptions of male nursing students for their retention in the nursing profession. It is recommended to use the results of this study in educational settings whenever male nursing students are. This may help the educators to have deeper understanding of the experience of male students which may reflect positively in improving students' clinical practice.

\section{References}

[1] Abushaikha, L, Mahadeen, A., AbdelKader, R. and Nabolsi, M. (2014) Academic Challenges and Positive Aspects: Perceptions of Male Nursing Students. International Nursing Review, 61, 263-269. https://doi.org/10.1111/inr.12098

[2] Solbraekke, K.N., Betty-Ann Solvoll, B.M. and Heggen, K.M. (2013) Reframing the Field of Gender and Nursing Education. Gender and Education, 25, No. 5. https://doi.org/10.1080/09540253.2013.819969

[3] Zamanzadeh, V., Azadi, A., Valizadeh, L., Keogh, B., Monadi, M. and Negarandeh, R. (2013) Choosing and Remaining in Nursing: Iranian Male Nurses' Perspectives. Contemporary Nurse, 45, 220-227. https://doi.org/10.5172/conu.2013.45.2.220

[4] Herakova, L. (2012) Nursing Masculinity: Male Nurses' Experiences through a CoCultural Lens. The Howard Journal of Communications, 23, 332-350. https://doi.org/10.1080/10646175.2012.722822

[5] Fawaz, M. and Hamdan-Mansour, A. (2016) Lebanese Student's Experience of Benefits of High Fidelity Simulation in Nursing Education: A Qualitative Approach. Open Journal of Nursing, 6, 853-862. https://doi.org/10.4236/ojn.2016.610084

[6] Ierardi, J.A., et al. (2010) Exploring Male Students' Educational Experiences in an Associate Degree Nursing Program. Journal of Nursing Education, 49, 215-218. https://doi.org/10.3928/01484834-20091217-04

[7] Brown, B. (2009) Men in Nursing: Re-Evaluating Masculinities, Re-Evaluating Gender. Contemporary Nurse, 33, 120-129. https://doi.org/10.5172/conu.2009.33.2.120

[8] Liminana-Gras, R., Sanchez-Lopez, M., Saavedra-San Roman, A. and CorbalanBerna, F. (2013) Health and Gender in Female-Dominated Occupations: The Case of Male Nurses. The Journal of Men's Studies, 21, 135-148. https://doi.org/10.3149/jms.2102.135

[9] Abu-Moghli, A., Khalaf, O., Halabi, A. and Wardam, L. (2005) Jordanian Baccalaureate Nursing Students' Perception of Their Learning Styles. International Nursing Review, 52, 39-45. https://doi.org/10.1111/j.1466-7657.2004.00235.x

[10] Ahmad, M. and Safadi, R. (2009) Entry Criteria and Nursing Students' Success. $J$ Med J, 43, No. 3.

[11] Doody, O., Slevin, E. and Taggart, L. (2013) Focus Group Interviews in Nursing Research: Part Analysis. British Journal of Nursing, 22, 266-269. https://doi.org/10.12968/bjon.2013.22.5.266

[12] Krueger, R. and Casey, M. (2009) Focus Groups: A Practical Guide for Applied Research. Sage Publications, Thousand Oaks, CA.

[13] McMurry, T. (2011) The Image of Male Nurses and Nursing Leadership Mobility. 
Nursing Forum, 46, 22-28. https://doi.org/10.1111/j.1744-6198.2010.00206.x

[14] Meadus, R. and Twomey, J. (2011) Men Student Nurses: The Nursing Education Experience. Nursing Forum, 46, 269-279. https://doi.org/10.1111/j.1744-6198.2011.00239.x

[15] Rowlinson, L. (2013) Lived Experience of Being a Nurse from a Male and Female Perspective. British Journal of Nursing, 22, 218-222. https://doi.org/10.12968/bjon.2013.22.4.218

[16] Battice, J. (2010) The Changing Face of Nursing in a Developing Country. Journal of Clinical Nursing, 19, 1765-1766. https://doi.org/10.1111/j.1365-2702.2009.02882.x

[17] Karabacak, U., Uslusoy, E., Alpar, S. and Bahcecik, N. (2012) Image of Nursing Held by Nursing Students According to Gender: A Qualitative Study. International Journal of Nursing Practice, 18, 537-544. https://doi.org/10.1111/ijn.12008

[18] Dyck, J.M., et al. (2009) Nursing Instructors' and Male Nursing Students' Perceptions of Undergraduate, Classroom Nursing Education. Nurse Education Today, 29, 649-653. https://doi.org/10.1016/j.nedt.2009.02.003

[19] Kada, O. (2010) Sex Role Orientation, Stressors and Resources in Male and Female Nurses. Review of Psychology (Croatia), 17, 97-104.

[20] Hamdan-Mansour, A., Hamaideh, S., Azzeghaiby, S., Hanouneh, S. and Aboshaiqah, A. (2015) Psychosocial Correlates of Motivation for Academic Accomplishment among University Students. Open Journal of Medical Psychology, 4, 1-8. https://doi.org/10.4236/ojmp.2015.41001

[21] Loughery, M. (2008) Just How Male Are Male Nurses? Journal of Clinical Nursing, 17, 1327-1334. https://doi.org/10.1111/j.1365-2702.2007.02250.x

[22] MacWilliams, B., Schmidt, B. and Bleich, M. (2013) Men in Nursing. American Journal of Nursing, 113, 38-44.

https://doi.org/10.1097/01.NAJ.0000425746.83731.16

[23] O’Lynn, Ch. (2004) Gender-Based Barriers for Male Students in Nursing Education Programs: Prevalence and Perceived Importance. Journal of Nursing Education, 43, 229-236.

[24] Rajapaksa, R. and Rothstein, W. (2009) Factors That Influence the Decisions of Men and Women to Leave Nursing. Nursing Forum, 44, 195-206. https://doi.org/10.1111/j.1744-6198.2009.00143.x

[25] Stott, A. (2007) Exploring Factors Affecting Attrition of Male Students from an Undergraduate Nursing Course: A Qualitative Study. Nurse Education Today, 27, 325-332. https://doi.org/10.1016/j.nedt.2006.05.013 
Submit or recommend next manuscript to SCIRP and we will provide best service for you:

Accepting pre-submission inquiries through Email, Facebook, LinkedIn, Twitter, etc. A wide selection of journals (inclusive of 9 subjects, more than 200 journals)

Providing 24-hour high-quality service

User-friendly online submission system

Fair and swift peer-review system

Efficient typesetting and proofreading procedure

Display of the result of downloads and visits, as well as the number of cited articles Maximum dissemination of your research work

Submit your manuscript at: http://papersubmission.scirp.org/

Or contact ojn@scirp.org 